\title{
O trabalho individualizado: da venda à dádiva*
}

\author{
Hermano Roberto Thiry-Cherques**
}

SumÁrio: 1. Introdução; 2. Método; 3. Elementos; 4. Quadro referencial; 5. Background; 6. Trabalho em equipe; 7. Trabalho virtual; 8. Resultados; 9. Discussão.

SumMARY: 1. Introduction; 2. Method; 3. Elements; 4. Framework; 5. Background; 6. Teamwork; 7. Telecommuting; 8. Results; 9. Discussion.

PAlaVRas-chaVe: trabalho; estruturalismo; gestão; administração; organizações.

KEY WORDS: work; structuralism; management; administration; organizations.

Este artigo estabelece um paralelo entre a categoria da dádiva, tal como definida por Marcel Mauss, e as estruturas relacionais do trabalho. Com base em pesquisa realizada junto a 122 organizações públicas e privadas, de diversos setores da economia, foi possível identificar: a superação da estrutura do trabalho em equipe (teamwork) e a prevalência de uma estrutura que privilegia o trabalho individualizado. A partir dessa constatação, o artigo discute a possibilidade de que o sistema de compra-venda do trabalho fragmentado esteja sendo substituído pelo sistema da dádiva-reconhecimento do trabalho individualizado. A pesquisa cujos resultados são comentados neste artigo indica que esse movimento não é fruto de uma evolução ou de uma circunstância momentânea, mas de uma mutação. Na tentativa de sobreviver às pressões do mercado, as organizações se encontraram na contingência de impor uma mudança radical na gestão de seus ativos. Como decorrência, a maneira como os recursos humanos são contratados, utilizados e descartados se alterou. A forma estrutural do trabalho-mercadoria vendido fragmentariamente se viu substituída pela estrutura em que o resultado do trabalho em lotes e frações integrais é transacionado contra recompensas que transcendem a simples remuneração.

* Artigo recebido em out. 2006 e aceito em mar. 2007.

** Professor titular da Ebape/FGV. Endereço: Praia de Botafogo, 190, 5a andar — Botafogo CEP 22250-900, Rio de Janeiro, RJ, Brasil. E-mail: hermano.roberto@fgv.br. 
Individualized labor: from sale to gift

This article establishes a parallel between the theory of gift exchange, as expounded by Marcel Mauss, and structural relationships in the workplace. Based on research conducted in 122 public and private organizations, in various sectors of the economy, it was possible to identify: the obsolescence of the teamwork structure and the prevalence of a structure that favors individualized labor. Based on this premise, the article discusses the possibility that the system of purchase-sale of fragmented labor is in the process of being replaced by the system of gift-recognition of individualized labor. The results of a research discussed in this article reveal that this movement is the product of a mutation rather than evolution or chance. In an attempt to withstand market pressures, organizations have been forced to impose radical change in the management of their assets. Consequently, the manner in which human resources are hired, used and discarded has changed. The structural model of labor-merchandise sold in a fragmented fashion has been replaced by a structure in which the result of labor is transacted in batches and integral fractions for a compensation that transcends mere remuneration.

\section{Introdução}

O trabalho e as formas de administrá-lo estão em constante transformação. Seguem os movimentos da sociedade, as imposições da vida econômica, o progresso das técnicas e das tecnologias. As relações estruturais na configuração dos sistemas produtivos e na disposição dos recursos humanos acompanham esses movimentos.

Neste artigo contribuímos conceitual e metodologicamente para o entendimento das implicações da transformação do trabalho na atualidade. Partindo da concepção do antropólogo e sociólogo Marcel Mauss ${ }^{1}$ sobre o sistema dádiva-recompensa como oposto ao de troca-venda, procuramos verificar as condições e possibilidade de que o trabalho e, conseqüentemente, a administração de recursos humanos, esteja sofrendo uma mutação em sua essência.

O método de investigação que utilizamos foi o do primeiro estruturalismo, na forma definida por Lévi-Strauss (1958, 1962a, 2003). Construímos três modelos de descrição de organização do trabalho, referentes: ao trabalho individual, ao trabalho em equipe e ao trabalho virtual. Confrontamos esses mo-

\footnotetext{
${ }^{1}$ Marcel Mauss (1872-1950), sociólogo francês, sobrinho de Durkheim, desenvolveu estudos antropológicos a partir da idéia de "fato social total".
} 
delos com o que ocorre efetivamente em 122 organizações governamentais e em empresas dos segmentos industrial, comercial e de serviços.

Como resultado, pudemos descrever a prevalência empírica de um modelo híbrido, uma forma de organização cujo atributo predominante é o da geração de frações integrais de serviços e lotes de produtos semi-acabados. Esse modelo reúne elementos estruturais do trabalho em equipe e do trabalho virtual. A sua principal característica é a agregação do resultado do esforço produtivo de conjuntos circunstanciais de trabalhadores.

Interpretando os resultados obtidos, verificamos que a estrutura das relações que caracteriza e determina esta forma de administrar o trabalho gera um modo de organizar com requerimentos e habilidades diversas das do trabalho em equipe e menos suscetível à alienação e à dependência que o caracterizam. Aparentemente a automação e a telemática tornaram organizacionalmente ineficaz o trabalho fragmentado, em que cada trabalhador integra o processo produtivo como um elemento indistinto. Como decorrência, a estrutura subjacente às transações entre o trabalhador e o contratante se reacomoda em um sistema de relação de trocas análogo ao da dádiva, tal como proposto por Mauss (2003). Uma estrutura que chamamos, por oposição ao trabalho individual e pelo distanciamento que apresenta, tanto do trabalho em equipe quanto do trabalho virtual, de trabalho individualizado.

Nos itens subseqüentes examinaremos: o método de investigação utilizado; o background teórico recente sobre os três modelos; os resultados obtidos; e oferecemos à discussão o esboço de um modelo explicativo, baseado no sistema da dádiva.

É possível que estejamos assistindo à decadência do trabalho em equipes. O desenvolvimento das ciências de gestão, o progresso tecnológico e as contradições inerentes às relações pessoais continuadas estão fazendo surgir novas formas de organizar a produção. A estrutura de relações do trabalho em conjunto e remunerado segundo o esforço despendido declina. A estrutura determinada pela retribuição individualizada de resultados vem tomando o seu lugar.

A pesquisa cujos resultados são comentados neste artigo indica que esse movimento não é fruto de uma evolução ou de uma circunstância momentânea, mas de uma mutação. Na tentativa de sobreviver às pressões do mercado, as organizações se encontraram na contingência de impor uma mudança radical na gestão de seus ativos. Como decorrência, a maneira como os recursos humanos são contratados, utilizados e descartados se alterou. A forma estrutural do trabalho-mercadoria vendido fragmentariamente se viu substituída pela estrutura em que o resultado do trabalho em lotes e frações integrais é transacionado contra recompensas que transcendem a simples remuneração. 
Três circunstâncias parecem estar produzindo o esgotamento do modelo do trabalho em equipe: a ineficácia das técnicas motivacionais requeridas pela produção em grupos; o incremento das pressões pela rentabilidade do trabalho; e as possibilidades abertas pelas novas tecnologias de informação.

Embora sejam inegáveis os benefícios individuais e sociais trazidos pela sinergia resultante da conjunção do esforço produtivo, que permitiu que grande número de trabalhadores adquirisse segurança e conforto, esse progresso não se deu sem ônus. O preço foi o sacrifício da individualidade em favor da entrega solidária ao grupo e à organização, a tal ponto que uma série de técnicas e de práticas motivacionais precisou ser desenvolvida para que as pessoas conseguissem trabalhar eficazmente umas com as outras, umas dependendo das outras. A artificialidade e as limitações desse processo constituem o primeiro fator da aparente exaustão do trabalho em equipes.

O segundo fator deriva do fato de que nos últimos anos a pressão pela economicidade do esforço produtivo e o desenvolvimento das técnicas de organização e gerência promoveram alterações na forma e na dinâmica organizacional. As organizações governamentais, as empresas e as demais instituições econômicas se interessam cada vez menos pela forma como o trabalho é realizado e cada vez mais com o valor que agrega. $O$ foco das atenções progressivamente se deslocou do processo para o resultado, da eficiência para a eficácia, do grupo para o indivíduo.

Por último, a tecnologia da informação, ao facultar o trabalho nãopresencial, induziu o distanciamento dos membros das equipes. Não só o trabalho teve que ser adaptado às novas exigências de produtividade, como se viu superado em eficácia pelas formas de administrar baseadas no tráfico de conhecimentos e na telemática. De sorte que as relações entre a organização, o trabalhador e o produto do trabalho se viram transformadas. Elas passaram, em grande medida, a obedecer a uma formação tripartite, que compreende não só a obrigação de trabalhar, decorrente da necessidade de sobrevivência, como a obrigação de reconhecer o resultado do trabalho, derivada do perfil sobre o qual se erigem, ainda que tacitamente, os contratos. A obrigação de retribuir, subsiste. Mas na estrutura que agora se delineia ela se funda no reconhecimento, que inclui, mas não se limita à remuneração.

\section{Método}

A proposta central do método estruturalista é a de considerar as relações entre entidades. Em vez de estudar um fenômeno ou elemento desconexo, o método se dirige para o entendimento da estrutura, da rede de correspondências entre 
elementos, que jaz sob o diretamente observável. Essas estruturas são apresentadas por esquemas lógico-matemáticos e interpretadas segundo as suas leis gerais de formação (Lévi-Strauss, 1958).

Os passos fundamentais do método são: a construção de modelos (idealizações) das relações entre elementos possíveis; a apropriação dos modelos mediante comparação, transposição, composição e demais operações lógicas, construídas a partir do empiricamente observado; e a sua objetivação, mediante a descrição e a interpretação das estruturas encontradas (Viet, 1973; Lévi-Strauss, 1962a, 1962b; Leach, 1973; Kronenfeld, 1979; Dosse, 1993).

\section{Elementos}

Na descrição dos modelos relacionais tomamos como atributo principal da forma de organizar o grau de dependência que tem cada trabalhador em relação à organização como um todo, com o produto do trabalho e com os demais trabalhadores.

Consideramos quatro elementos de diferenciação do trabalho: domínio, atitude, relação e foco (quadro referencial). O domínio se refere ao grau de controle sobre o próprio trabalho: o trabalhador detém o controle total sobre a forma de trabalhar e sobre o produto do trabalho, ou é controlado por outro trabalhador, ou, enfim, é controlado somente pelo resultado do trabalho que apresenta. A atitude está referida à conduta manifesta do trabalhador: individualista, coletivista ou profissional, isto é, nem completamente isolada nem dependente de grupos de trabalho. A relação refere-se ao grau de dependência em relação aos demais trabalhadores. O foco, ao interesse primordial do trabalhador em cada modelo de organização: o produzir, o integrar-se ou o interagir com os demais trabalhadores.

Figura 1

Modelos de organização do trabalho

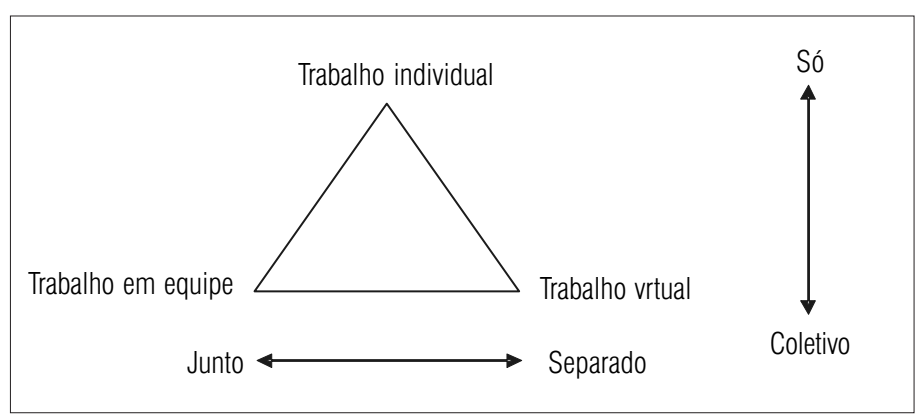

RaP Rio de Janeiro 4l(4):707-31, Jul./Ago. 2007 


\section{Modelos}

Consideramos três modelos ou possibilidades de relações entre os elementos de diferenciação: trabalho individual; trabalho em equipe; trabalho virtual (figura 1).

Trabalho individual. A característica básica do trabalho individual é a independência do trabalhador. Uma liberdade assente sobre o planejamento do trabalho e o domínio pleno das técnicas de produção. O trabalhador tem sob seu controle as quatro causas aristotélicas: planifica o modo de produzir, escolhe a matéria a ser trabalhada, determina a forma final e exerce o esforço produtivo. $\mathrm{O}$ atributo do trabalho individual ou trabalho de ofício é a autarquia. O seu foco está dirigido para a produção. O trabalhador está só.

Trabalho em equipe. A tônica do trabalho em equipe é a de um coletivismo dependente. Uma forma de trabalho determinado pela harmonização da tarefa dividida. Os trabalhadores compartilham a empreitada. Cada um detém um fragmento da responsabilidade e do esforço produtivo. $\mathrm{O}$ atributo do trabalho em equipe é a interdependência. $\mathrm{O}$ seu foco esta dirigido à integração do esforço individual, à sinergia com os demais trabalhadores nas organizações. $\mathrm{O}$ trabalhador nunca está só. Está sempre junto aos companheiros de trabalho.

Trabalho virtual. A particularidade do trabalho virtual é o profissionalismo emancipado. Um profissionalismo que assenta no poder decisório sobre o conteúdo e a forma do produzir. O trabalhador tem sob seu domínio a técnica e o controle do seu próprio esforço. $\mathrm{O}$ atributo do trabalho virtual é a autonomia. O seu foco está dirigido para a comunicação, para a interação com os demais trabalhadores e com as organizações. O trabalhador não está junto com os companheiros. Tampouco compartilha o espaço produtivo com os demais trabalhadores. Ele está afastado.

\section{Quadro referencial}

Relacionando os elementos característicos das formas de trabalhar e os modelos de organização do trabalho, obtivemos uma matriz determinante de cada modelo, com os atributos correspondentes.

\begin{tabular}{|llll|}
\hline \multicolumn{4}{|c|}{ Determinantes das modalidades do trabalho } \\
\hline Determinante & Trabalho individual & Em equipe & Virtual \\
\hline Domínio & Controle total & É controlado & Controle seletivo \\
Atitude & Individualista & Coletivista & Profissional \\
Forma de relação & Independência & Dependência & Emancipação \\
Foco da ação & Produzir & Integrar & Interagir \\
\hline
\end{tabular}


A partir desse quadro, procuramos verificar as situações predominantes nas formas de trabalhar nas empresas e organizações públicas. Na pesquisa foram realizadas entrevistas e aplicados questionários a executivos (gerentes/ técnicos) em um sistema de autodeclaração (self-report), representativos de 122 organizações atuantes no Rio de Janeiro.

\section{Background}

Os elementos do trabalho individual são residuais no discurso contemporâneo sobre as formas de trabalho. Ele está ausente das organizações, ainda que prospere na economia, seja como trabalho de ofício, seja como auto-empreendimento.

A maior parte das investigações da atualidade se centra nas benesses e nas dificuldades inerentes ao trabalho em equipe e, em menor escala, ao trabalho virtual.

\section{Trabalho em equipe}

As análises sobre o trabalho em equipe indicam um esforço, voluntário ou não, para remoção das situações de conflito, endêmicas em grupos (Jehn, 1995; Earley e Singh, 1995). Sob a ótica do interesse do trabalhador, o balanço dos aspectos negativos e positivos do trabalho em equipe é inconclusivo. De um lado, a tirania dos grupos tem sofrido pesadas críticas (Sinclair, 1992), tanto devido aos custos emocionais resultantes do controle ostensivo (Barker, 1993) quanto da pressão do grupo sobre o indivíduo (Barron e Gzerde, 1997). De outro, a estruturação de equipes tem sido considerada fator de humanização e de incremento dos resultados do esforço produtivo (Katzembach e Smith, 1993) devido ao compromisso (commitment) (Wood e Albanese, 1997), à sinergia (Drucker, 1988) e à flexibilidade (Reed, 1992).

O clima e a situação resultantes das interações emocionais no grupo, que podem estimular ou não a produtividade (Sutton, 1991), assumem características distintas, já fartamente recenseadas (Sedikides e Brewer, 2001). O cerne insolúvel dos problemas apresentados pelo trabalho em equipe parece estar centrado na emoção e na disposição compartilhada, decorrentes da transferência de estados afetivos entre os membros de grupos (Bartel e Saavedra, 2000). Há evidências de que a disposição e o humor são comunicados aos outros por meio de expressões faciais, vocais e de postura. Um "contágio emocional" na constituição das equipes, que resulta em uma convergência de humor (mood convergence) (Barsade, 2002; Bartel e Saavedra, 
2000) que limita o desenvolvimento da produtividade do trabalho, tanto pela instabilidade resultante desse processo, quanto pela tendência de fratura no esforço motivacional.

\section{Trabalho virtual}

Os estudos sobre o trabalho virtual datam dos anos 1980, mas só a partir da década de 1990 se tornaram mais efetivos. Houve, de início, como é natural, grande entusiasmo em relação às suas possibilidades, o que toldou a objetividade das análises e, até mesmo, a definição precisa do objeto. Só no final da década se estabeleceu o entendimento mais ou menos consensual do trabalho virtual, englobando o que se realiza em organizações virtuais - definidas como redes de firmas independentes que põem em comum seus recursos e competências graças às tecnologias de informação (Saravia, 2002:19) em que indivíduos distantes uns dos outros trabalham em função de uma meta comum (Staples, Hulland e Higgins, 1999:758) — e o trabalho realizado em organizações convencionais, mas sem o contato físico entre os trabalhadores (Jackson, 1999).

Embora estudos sobre o trabalho virtual e questões relativas ao reconhecimento e recompensa (organizational justice) (Kurland e Egan, 1999), problemáticos devido às dificuldades de monitoramento e ao isolamento do trabalhador (Tomaskovic-Devery e Risman, 1993) e às necessidades específicas de capacitação, especialmente em TI (Staples, Hulland e Higgins, 1999), hajam concluído que o trabalhador virtual percebe-se como recebendo igual ou maior reconhecimento e respeito do que o trabalhador em equipe, a falta de contato pessoal não é aceita, ou ainda não é aceita com facilidade pela maioria dos trabalhadores. Ao contrário dos que acreditam que o trabalho virtual possa corresponder ao ideal weberiano do trabalho "de acordo com regras calculáveis e sem preocupação com as pessoas" (Weber, 1948:80), ele apresenta várias dificuldades. Pesquisas realizadas nos anos 1980 e 1990 (Kurland e Egan, 1999) indicaram que o trabalho virtual acarreta redução do estresse, flexibilização, aumento do tempo útil e redução de conflitos familiares entre os trabalhadores. Mas a vulnerabilidade no que se refere ao compartilhamento de informações e conhecimento, ao compromisso (commitment), à defesa da propriedade de tecnologia, ao segredo de planos de negócios e de propriedade intelectual veio a ocasionar um incremento e uma sofisticação das formas de controle (Jackson, 1999). Os custos daí decorrentes, notadamente a necessidade de gerar informações básicas e de investir em controle a distân- 
cia vieram se somar à perda de produtividade devida ao estresse resultante do isolamento do trabalhador.

Os ganhos de tempo e de produtividade devidos às facilidades de acesso à informação, à menor distração, à maior flexibilidade para organizar o tempo e o espaço do produzir (Venkatesh e Vitalavi, 1992) e a passagem de uma comunicação falha, não documentada e pessoal para a comunicação sistemática, documentável e formal, se, por um lado, restringem a perda de tempo útil e diminuem o impacto de fenômenos como o dos boatos e o da falta de empatia, por outro, individualizam as preocupações, antes compartilhadas pela equipe, em relação à qualidade do tempo despendido e em relação à autenticidade e à originalidade da informação e do processo de comunicação. O fato é que, apesar do que promete idealmente, o trabalho virtual ainda apresenta muitos problemas a serem equacionados e superados para que possa levar a ganhos marginais de produtividade significativos.

Em síntese, os estudos e pesquisas que mencionamos indicam que as formas estruturais de organizar o trabalho se encontram em momentos distintos. O trabalho individual interno às organizações, do trabalhador isolado e independente desapareceu, tragado por sua própria ineficiência, ou, pelo menos, desapareceram os estudos e análises a ele referidos. O trabalho em equipe, que dominou a segunda metade do século $\mathrm{XX}$, colhido pela pressão competitiva da economia, aparentemente esgotou as suas possibilidades de desenvolvimento e continuidade. O trabalho virtual ainda não pode superar as barreiras de ordem psicológica e cultural que a ele se interpõem.

\section{Resultados}

Os resultados obtidos indicam um deslocamento de controle sobre o esforço para a regulação de resultados. Uma forma de ordenar o trabalho que já não é a do trabalho em equipe sem chegar a ser a do trabalho virtual. Em face da interação a distância entre o trabalhador e a organização, o traço característico desse modelo é dado pela entrega em lotes do serviço ou do produto (semi-acabado). O trabalho não é uno, como no caso do indivíduo que produzia sozinho, tampouco é fragmentado, como no caso da equipe de produção, que trabalha permanentemente em conjunto, mas não alcança o afastamento completo, característico do trabalho virtual. O trabalhador já não pertence a uma equipe, mas a um conjunto de indivíduos que, inclusive, competem entre si.

Na tabela 1 estão dispostas as possibilidades de combinação dos atributos de cada modelo, e os resultados obtidos. 


\begin{tabular}{|c|c|c|c|c|c|}
\hline \multicolumn{6}{|c|}{$\begin{array}{l}\text { Tabela } 1 \\
\text { Matriz de co-possibilidades: } \\
\text { resultados obtidos }\end{array}$} \\
\hline A1B1C1D1 & 1 & A2B1C1D1 & & A3B1C1D1 & \\
\hline A1B1C1D2 & & A2B1C1D2 & & A3B1C1D2 & \\
\hline A1B1C1D3 & & A2B1C1D3 & & A3B1C1D3 & \\
\hline A1B1C2D1 & & A2B1C2D1 & 9 & A3B1C2D1 & 3 \\
\hline A1B1C2D2 & & A2B1C2D2 & & A3B1C2D2 & \\
\hline A1B1C2D3 & & A2B1C2D3 & & A3B1C2D3 & \\
\hline A1B1C3D1 & & A2B1C3D1 & & A3B1C3D1 & 1 \\
\hline A1B1C3D2 & & A2B1C3D2 & 1 & A3B1C3D2 & \\
\hline A1B1C3D3 & & A2B1C3D3 & & A3B1C3D3 & \\
\hline A1B2C1D1 & & A2B2C1D1 & & A3B2C1D1 & \\
\hline A1B2C1D2 & & A2B2C1D2 & & A3B2C1D2 & \\
\hline A1B2C1D3 & & A2B2C1D3 & & A3B2C1D3 & \\
\hline A1B2C2D1 & & A2B2C2D1 & 8 & A3B2C2D1 & 5 \\
\hline A1B2C2D2 & & A2B2C2D2 & 11 & A3B2C2D2 & 7 \\
\hline A1B2C2D3 & & A2B2C2D3 & & A3B2C2D3 & \\
\hline A1B2C3D1 & & A2B2C3D1 & 1 & A3B2C3D1 & 2 \\
\hline A1B2C3D2 & & A2B2C3D2 & & A3B2C3D2 & 1 \\
\hline A1B2C3D3 & & A2B2C3D3 & & АЗВ2C3D3 & \\
\hline A1B3C1D1 & 2 & A2B3C1D1 & 2 & A3B3C1D1 & 3 \\
\hline A1B3C1D2 & & A2B3C1D2 & & A3B3C1D2 & \\
\hline A1B3C1D3 & 5 & A2B3C1D3 & & A3B3C1D3 & \\
\hline $\mathrm{A} 1 \mathrm{~B} 3 \mathrm{C} 2 \mathrm{D} 1$ & & A2B3C2D1 & 9 & A3B3C2D1 & 11 \\
\hline A1B3C2D2 & & A2B3C2D2 & 19 & A3B3C2D2 & 13 \\
\hline A1B3C2D3 & & A2B3C2D3 & 1 & A3B3C2D3 & 1 \\
\hline A1B3C3D1 & & A2B3C3D1 & & A3B3C3D1 & 4 \\
\hline A1B3C3D2 & & A2B3C3D2 & 3 & A3B3C3D2 & \\
\hline A1B3C3D3 & & A2B3C3D3 & & АЗВ3С3D3 & 6 \\
\hline
\end{tabular}

\section{Modelo do trabalho individual (série 1)}

A1: o trabalhador tem o controle total sobre o processo produtivo.

B1: a atitude preponderante é a individualista (isolamento do trabalhador).

C1: a forma de relação preponderante entre o trabalhador e a organização é a da independência.

D1: o foco principal do trabalho está centrado na produção. 


\section{Modelo do trabalho em equipe (série 2)}

A2: o trabalhador é controlado pela organização.

B2: a atitude preponderante é a coletivista (gregarismo do trabalhador).

C2: a forma de relação preponderante entre o trabalhador e a organização é a da dependência.

D2: o foco principal do trabalho está centrado na integração.

\section{Modelo do trabalho virtual (série 3)}

A3: o controle do trabalhador é seletivo.

B3: a atitude preponderante é a profissional (distanciamento do trabalhador). C3: a forma de relação preponderante entre o trabalhador e a organização é a da emancipação (o trabalhador nem é dependente nem totalmente independente da organização).

D3: o foco principal do trabalho está centrado na comunicação.

Considerando como atributos determinantes do trabalho individualizado tanto o controle parcial, resíduo do trabalho em equipe, quanto o controle seletivo (A2, A3), o distanciamento do trabalhador, característico do trabalho virtual (B3), a dependência (C2) e a integração característica do trabalho em equipe, e o foco, tanto na produção, resíduo do trabalho individual, quanto na integração, típica do trabalho em equipes (D1, D2), temos a estrutura híbrida, o trabalho individualizado, cobrindo $75 \%$ das indicações da pesquisa.

\begin{tabular}{|cr|}
\hline \multicolumn{2}{|c|}{$\begin{array}{c}\text { Tabela } 2 \\
\text { Distribuição das estruturas organizacionais: } \\
\text { dados agregados }\end{array}$} \\
\hline Individual (1) & 1 \\
Combinação individual/equipe (1 e 2) & 10 \\
Combinação equipe/individual (2 e 1) & 10 \\
Equipe (2) & 11 \\
Combinação equipe/virtual (2 e 3) & 41 \\
Combinação virtual/equipe (3 e 2) & 32 \\
Virtual (3) & 6 \\
Combinação virtual/individual (3 e 1) & 13 \\
Combinação individual/virtual (1 e 3) & 5 \\
\hline
\end{tabular}


Distribuição das estruturas

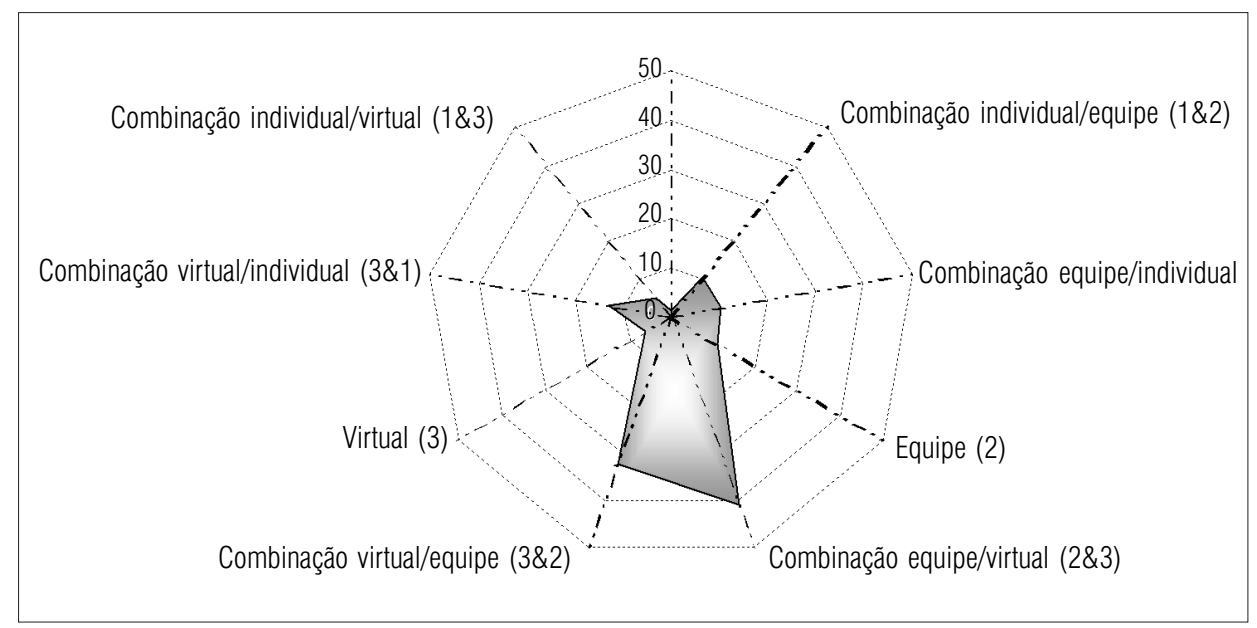

O modelo provém de um contexto em que as organizações, em vez de buscar o controle da cadeia de valores mediante a propriedade de negócios, tendem a adquirir recursos e capacidades estratégicas mediante a criação de redes de associados independentes (fornecedores, clientes, parceiros) para compartilhar habilidades, custos e acessos a mercados. Graças à tecnologia da informação, as organizações já podem ambicionar reter somente as funções administrativas críticas para sua competência competitiva e que não podem ser mais eficientemente desempenhadas por subcontratados. No campo específico do trabalho, as organizações contratam e descartam associados e empregados com velocidade crescente, procurando alavancar vantagens competitivas.

O trabalho individualizado resultante desse processo tem características próprias. A ele não se aplicam os padrões de expectativas acerca dos papéis, escopo, admissão de membros e objetivos das equipes, reveladas pelos estudos sobre cultura organizacional (Gibson e Zellmer-Bruhn, 2001). As metáforas militares, usuais no trabalho em equipe (aliança, comando, mobilização), são substituídas pela idéia de sistema; as metáforas familiares (fraternidade, família, irmandade), pela de distribuição eqüitativa; as esportivas (time, competição, jogadores), pela idéia de rede; as metáforas associativas (círculo, conselho, franquia), pela de sociedade, e as metáforas comunitárias (companheiros, comunidade, amigo), pela de parceria. Mas a principal particularidade que, a nosso ver, caracteriza o trabalho individualizado é a da forma como o trabalho 
é transacionado, os bens e valores pelos quais o trabalho é trocado, como argumentamos a seguir.

\section{Discussão}

\section{Dádiva e comércio}

Em seu "Ensaio sobre a dádiva" Mauss (2003) deu uma contribuição decisiva para os rumos do pensamento ocidental. O método que usou antecipou o estruturalismo. As conclusões a que chegou instruíram a visão das ciências culturais sobre as relações de troca, sobre os fatos sociais e sobre a relatividade do progresso.

No ensaio, Mauss discute o que poderia existir na coisa dada que faz com que o donatário a retribua. Nas suas considerações sobre os laços entre pessoas e sobre a maneira como os objetos e os serviços são transacionados, Mauss (2003:188) desenvolveu uma distinção entre o que é trocado como mercadoria e o que é oferecido como dádiva. Demonstrou, entre outras coisas, que a dádiva só em teoria é voluntária, que na prática é uma obrigação social, e que os objetos e serviços oferecidos nunca se separam das pessoas que os transacionaram. Mais do que isso: evidenciou que o sistema de dádivas permanece embutido na materialidade inumana da nossa sociedade.

Antes de vermos como esse sistema se aplica aos dados da pesquisa que relatamos, é preciso um esclarecimento. Embora o termo /dádiva/ evoque a imagem de um presente, de um objeto monoutilitário, dado conscientemente com algum grau de cerimônia, sem que se espere retribuição (Carrier, 1991:122), a noção técnica é diferente. A dádiva é um objeto ou um serviço, útil ou supérfluo, transacionado como parte de uma relação não unicamente nem essencialmente monetária ou material. Ela resulta de uma obrigação societária, não necessariamente jurídica. A recusa da dádiva, de recebê-la e de retribuí-la, implica o desprezo social e a culpa. O sistema da dádiva compreende a tripla obrigação de dar, de receber e de retribuir (Caillé, 1998:26).

Mauss verificou que nas sociedades ditas primitivas e pré-capitalistas as trocas são essencialmente fundadas no sistema da dádiva enquanto na sociedade capitalista as transações são primordialmente fundadas na compra e venda (Mauss, 2003:303). No entanto, assinala, o sistema de dádivas permanece, ainda que como resquício, na nossa sociedade. Isto porque existem posses (possessions) que são transacionadas como dádivas e existem bens, que são transacionados como mercadorias, que são comprados e vendidos. A nossa sociedade é regida pela troca de mercadorias, enquanto as sociedades pré- 
capitalistas foram e são regidas pela troca de posses. Mas a dádiva nas sociedades modernas estaria "embutida na compra e venda" que não é independente dela (Mauss, 2003:294).

\section{Paralelismos}

Com uma freqüência que os teóricos contemporâneos insistem em desconhecer, a forma de pesquisar e os achados de Mauss ressurgem a cada passo em que as investigações das ciências humanas e sociais se desenvolvem e ampliam seus horizontes. Foi o que ocorreu ao interpretarmos os resultados da pesquisa aqui relatados.

O que aproxima Mauss do que efetivamente acontece nas organizações contemporâneas é que ele não considera, como o marxismo e suas derivações e como a socioeconomia liberal e suas variações, que as sociedades apresentem perfis homogêneos e os seus membros, condutas discretas. Mauss se antecipa ao que vivemos hoje, o momento em que o que faz funcionar as organizações contemporâneas e dá vida aos mercados econômicos não é nem a rígida disciplina estatal nem a abstrata lei econômica da oferta e da procura, mas a cadeia de dependências e relações de confiança de que são feitas as redes (Caillé, 1998:15); em que, sob termos como /empresa/, /agência/, /órgão/, seja em que regime econômico for, existe uma pluralidade de formas de organizar e de modos de trabalhar, de estruturas e de valores. Um momento em que a vida organizacional não é só dada pela circulação de bens, mas também por pessoas, símbolos e valores; em que as transações são complexas e as formas e modos de trabalhar, praticamente infinitos.

O sistema da dádiva pode parecer ingênuo, mas a verdade é que ninguém documentou até agora existência de uma "economia natural" da troca. Como argumenta Mauss (2001:356), se há algo que seja "natural", no sentido de ser inerente a muitas sociedades, arcaicas ou não, é o sistema de dádiva. Não fomos os primeiros e, certamente, não seremos os últimos a invocar o sistema da dádiva. Blau (1964:89-108), o grande teórico das organizações formais, ao estudar o poder na vida social lhe dedica praticamente um capítulo inteiro. Isso decorre, provavelmente, da abrangência do fenômeno. É que as trocas no sistema de posses-dádivas não contemplam unicamente riquezas, senão que incluem amabilidades, serviços, cargos, demonstrações de prestígio, amuletos, alimentos e até mulheres e crianças.

O sistema da tripla obrigação de dar, receber e retribuir expõe e garante a circulação e a abundância das riquezas (Mauss, 2003:191-203). Mas este é apenas um dos aspectos das prestações e contraprestações. O sistema não se- 
para, como nós o fazemos, as pessoas e as coisas. Na medida em que as pessoas nunca se dissociam inteiramente das posses, a dádiva tem, principalmente, a função social de fortalecer laços (Mauss, 2003:235). O mesmo acontece com o trabalho individualizado da atualidade, dado que os laços filiais, que, no trabalho por equipe unem o trabalhador à organização e os laços fraternais, que unem o trabalhador aos companheiros, com o distanciamento (atributo B3), imposto pela demanda por produtividade marginal crescente e possibilitado pela telemática, se vêem dissolvidos.

Enquanto o sistema de compra e venda está limitado à esfera econômica, o sistema de dádiva e retribuição alcança as esferas social, política e moral. Mauss entende a troca no sistema de posse-dádiva como um contrato, no sentido que lhe dá Rousseau, de uma aliança voluntária. Contratar (- com, junto, - trahere, trazer) equivale a pactuar (— pangere, estreitar), a contrair um compromisso (Mauss, 2003:303). Mais tarde, Lévi-Strauss (1967) generalizará a idéia deste contrato com o nome de "princípio de reciprocidade" (Lanna, 2000:178). É este pacto recíproco que caracteriza a passagem da forma do trabalho controlado pela organização (atributo A2) para o controle seletivo (atributo A3) sobre os resultados do trabalho.

O sistema de posse-dádiva obriga a dar, mas também a receber e a retribuir. Não se pode recusar uma dádiva, como a da hospitalidade, por exemplo, sob pena de ofender o "doador". Na sociedade primitiva, diferentemente do que ocorre na economia liberal, não são os indivíduos, mas as coletividades, as "pessoas morais", representadas pelos chefes, que se obrigam mutuamente. A não-retribuição implica sanções sociais e espirituais. A perda do "mana" ou do "hau" nas sociedades primitivas é similar à perda de prestígio, do respeito e do afeto na nossa sociedade (Mauss, 2003:195). A dádiva produz alianças políticas, matrimoniais, religiosas, diplomáticas, mas, também, alianças econômicas e institucionais como a do contrato e, cada vez mais, como a do emprego volátil da atualidade, que nem o empregador nem o trabalhador individualizado esperam que seja eterno, mas que se renove com freqüência.

O sistema de mercadoria-venda é imediato, mas o sistema de possedádiva, como a retribuição é mediata, implica a idéia de crédito, de um "consórcio adiado". Outra noção implicada no sistema de dádiva é a valorização do doador. O valorizado, o que aufere maior status é o que dá mais, não o que ganha mais (Mauss, 2003:240). Enquanto no sistema de mercadoria-venda as transações são interesseiras e independem de quem e com quem a troca é feita, nas transações do sistema posse-dádiva os objetos e serviços são inalienáveis, associando o doador e o donatário e definindo a relação existente entre eles (Carrier, 1991:121). 


\section{O trabalho vendido e o trabalho retribuído}

Na nossa sociedade vemos a todo o momento resquícios do sistema de possedádiva. Estão presentes no "nexum" do direito romano, marcado pelas exigências de testemunhas, de solenidades. Nós o vemos nos termos ritualísticos dos contratos legais, nas cerimônias, selos e carimbos que acompanham ainda muitas das nossas trocas e que nada têm a ver com a compra e venda. Na nossa vida social o convite e a cortesia devem ser retribuídos. Temos obrigações de dar, receber e retribuir presentes em datas festivas, de dar esmolas, de colaborar, de dar cumprimentos, de oferecer homenagens, de dar sinais de reconhecimento do status etc. A dádiva está em toda a parte. Na atenção para com os outros, na esperança da reciprocidade. A dádiva constitui o sistema de relações propriamente sociais, na medida em que estas são irredutíveis às relações de interesse econômico ou de poder (Godbout, 1999:22).

A base da identidade pessoal nas sociedades primitivas e pré-capitalistas - a estrutura do parentesco - foi substituída na nossa sociedade por institutos como a família, o círculo de amizades, as relações de vizinhança e, especialmente na sociedade pós-industrial, pelas alianças derivadas das relações empregatícias (o tipo de vínculo), ocupacionais (o tipo de trabalho) e organizacionais em geral. Durante muito tempo o trabalho foi coisificado para ser consumido. Completada a venda (a prestação) ou o aluguel (o emprego) do trabalho, dissolvia-se imediatamente o laço entre as partes. Mas, na medida em que é o resultado e não o esforço que passa a contar, há um coeficiente de arrasto no produto do trabalho (atributo D1) que mantém se não os laços, pelo menos a memória da integração plena, característica do trabalho em equipe (permanência do atributo D2).

Na forma de trabalhar que identificamos na pesquisa - o trabalho individualizado - o maior "controle ou posse" do bem ou do serviço produzido deriva não de uma maior ou menor "naturalidade" ou "moralidade" do regime - pré-capitalista, capitalista, socialista - mas da lógica mesma da forma de produzir e de organizar a produção (atributos A2 e A3). O trabalho individualizado, como o trabalho individual, por sua própria natureza, tende ao sistema de dádiva-retribuição enquanto o trabalho em equipe se presta mais ao sistema de venda-pagamento. É que, regido pelo resultado e não pelo esforço, pelo produto e não pela força de trabalho despendida, o trabalho é transacionado como um serviço inalienável do trabalhador entre partes mutuamente obrigadas: a dar, a receber, a retribuir. O valor de troca, o preço monetário de um bem, é idêntico ao valor de troca de qualquer outro bem de mesmo preço. Mas o valor de troca não é o único valor de um bem. Da mesma forma que preferimos comprar o pão em um determinado estabelecimento, que, para nosso gos- 
to é "melhor" do que de outro, embora custe o mesmo, o resultado do trabalho entregue em lotes carreia em si valores inalienáveis, qualidades que não são expressas unicamente pela remuneração do trabalhador. Carrega a marca, a identidade do trabalhador.

$\mathrm{Na}$ atualidade, a produção existe independente do uso. Ela é um fim em si mesma. O produtor ignora o destino final e o objetivo derradeiro de suas atividades. A cultura organizacional repousa sobre um sistema que cria necessidades artificiais para escoar a produção. Já na década de 1930, Mayo (1933) demonstrou que a produtividade aumenta à medida que os trabalhadores têm a ilusão de que alguém se interessa por eles. Hoje sabemos que as redes de afinidades intra-organizacionais não são regidas nem exclusiva nem principalmente pelas hierarquias. Que elas assentam sobre o vínculo, sobre o reconhecimento, que é tanto o reconhecimento que recebemos dos outros, do colega ou do dirigente, como o que manifestamos a alguém ou a algo, como quando reconhecemos uma dívida (Godbout, 1999:180).

No pré-capitalismo o trabalho era ainda uma propriedade do trabalhador que o dava a uma outra pessoa ou à sociedade que lhe retribuía com alimento, abrigo, convívio ou com algum símbolo, incluindo aí alguma moeda de troca, como o sal. No capitalismo, o trabalho foi definido em termos do valor de uso e do valor de troca e não em termos da identidade de quem o transaciona: o trabalhador e o contratante. Na forma tardia (ou deteriorada) do capitalismo em que vivemos, é cada vez mais evidente, como dizia Mauss (2003:306), que "as instituições econômicas (...) não são governadas pelo racionalismo econômico do qual se costuma fazer a teoria". Na atualidade, como sempre, o trabalhador deve sua vida e a sua sobrevivência à coletividade de um lado e aos empregadores de outro. Ele depende dos outros atores econômicos, dos colegas e da organização (atributo C2). Mas essa dependência é mútua. O salário não quita os seus serviços. São devidos a ele a segurança contra o desemprego, a doença, a velhice e a morte (Mauss, 2003:296). Como queria Mauss (2003:298), se, hoje como nunca antes, é preciso que o trabalhador aprenda a contar mais consigo mesmo do que com os outros, ele exige que se lhe assegurem os costumes do "dispêndio nobre", as formas e as leis de seguridade.

\section{A dádiva do trabalho}

Não há distinção entre a dádiva de um objeto e a dádiva do trabalho. Os laços que unem o trabalhador individualizado às organizações continuam a ser regidos pelas condições de produção e de distribuição, isto é, pelo sistema de 
classes e pela divisão do trabalho. Mas o sistema da dádiva coloca em primeiro lugar o trabalho, a "doação" do trabalho, mas que, a não ser no caso da caridade, não é um presente, algo que é dado na expectativa da compensação. As transações que envolvem o dar, o receber e o retribuir são muito mais complexas do que a simples troca do trabalho-mercadoria por dinheiro.

Nas organizações contemporâneas, embora se torne cada vez mais evidente, documentado e controlado o que é feito e por quem, nem todo trabalhador está ligado diretamente à produção, ao produto ou serviço gerado. Existem pelo menos quatro níveis de proximidade com os bens produzidos ou transacionados: o da geração/produção, o do apoio à produção, o administrativo e o de serviços. O trabalho individualizado aproxima e confunde esses níveis. Tarefas como, por exemplo, o apoio à produção (a manutenção de equipamentos), administrativas (a contabilidade) e serviços (os transportes) ou bem estão a cargo do produtor, como no trabalho individual, ou são entregues como "produtos", como unidades discretas, como bens componentes, não, ou não somente como fragmentos, suportes ou acessórios do trabalho alheio.

A força do trabalho individualizado é uma posse alienada contra uma retribuição, não uma mercadoria vendida contra uma recompensa. Uma pessoa que presta serviços à outra espera uma retribuição, ou seja, obriga-a. Para desobrigar-se, aquele que recebe um bem ou serviço deve retribuir (Blau, 1964:89). Há, portanto, a obrigação de dar, a obrigação (contratual) de receber e a de retribuir. $\mathrm{O}$ reconhecimento não é somente monetário e o produto do trabalho é facilmente reconhecível no produto ou serviço final a ser distribuído e consumido. Ao contrário do que acontece no trabalho em equipe, no trabalho individualizado verifica-se a personalização do trabalhador. Isso sempre foi assim para o restaurante que dependia do seu chef, para a oficina que dependia do seu artista lanterneiro. Agora, e cada vez mais, isso é verdade para o banco que depende do seu gerente de carteira, para o escritório que depende do seu web designer, para a multiplicidade de organizações, projetos e tarefas em que o ocupante do posto de trabalho não é indiferente. Não se trata da emancipação do trabalho virtual (atributo C3) nem da independência do trabalho individual (C1). Mas, tampouco, é a dependência unidirecional do trabalho em equipe. O que se verifica é uma dependência mútua, um entrelaçamento entre os interesses do trabalhador, dos demais trabalhadores e das organizações a que servem.

Prova disso é que os laços devem ser constantemente reforçados. A autonomia e a auto-suficiência dão ao trabalhador individualizado um poder que constitui uma vulnerabilidade para a organização. A ênfase no domínio da informação decorre, ao contrário do que possa parecer, da facilidade e do baixo custo de implantação dos sistemas de telemática. Embora 95\% da informa- 
ção estratégica sejam obtidos de fontes públicas (instituições governamentais, bases de dados, mídia etc.) (Fitzpatrick e Burke, 2003), e as organizações só disponibilizem a informação necessária ao trabalho, grande parte dos recursos informacionais é perdida com fraudes e corrupção, mas principalmente pela negligência. Somam-se a essas perdas as dificuldades de controle devidas à velocidade das transações, de forma que as organizações se vêem no imperativo de desenvolver sistemas de confiança mútua e comunicação aberta, única possibilidade de aumentar a flexibilidade, a transferência de informação e a sinergia competitiva. Uma circunstância que torna antieconômico o controle do trabalho e que transcende a simples troca do seu resultado por remuneração. Um sistema em que é preciso oferecer mais do que a disponibilidade para o trabalho, em que é preciso receber mais do que esforço diligente, em que é preciso retribuir com algo que não seja só o pagamento em dinheiro.

\section{O outro lado da moeda}

Também os resquícios negativos do sistema da dádiva estão presentes no trabalho individualizado. Notemos, em primeiro lugar, que o sistema de possedádiva nada tem de caridoso. Ele é egoísta, efêmero e competitivo.

As relações de trabalho contemporâneas se dão em um contexto de ambivalência irredutível. De um lado, a nossa sociedade é o reflexo de uma economia onde os interesses instrumentais são hierarquicamente secundários em relação ao que se poderia chamar de interesse de forma ou de apresentação de si. De outro, como nas cerimônias de troca, o potlatch, ${ }^{2}$ emblemático do sistema de dádivas, os contratos apenas fixam "por instantes" uma hierarquia. O potlach é mais importante e mais freqüente onde a hierarquia (como nas organizações contemporâneas) não é estabelecida e rígida, onde há menor centralização política. Como no sistema da dádiva, os empregadores e colegas, contratantes e parceiros são, ao mesmo tempo, aliados e rivais (competidores). A estrutura de relações de trabalho encerra uma competição individualista pelo melhor resultado, pela honra profissional, pelo próximo contrato. A retribuição pelo trabalho transcendendo a recompensa pelo esforço (ou a simples presença) embute nele a dimensão política, social, psicológica do retorno (Caillé, 1998:14-18).

\footnotetext{
${ }^{2}$ Uma festa em que se repartem bens em troca de honras, prestígio, poder, compromissos e de préstimos e outros bens a serem retribuídos no futuro (Mauss, 2001:353).
} 
Para Mauss, nenhuma sociedade poderia edificar-se exclusivamente sobre o registro do contrato e do utilitário. Qualquer ordem social só pode surgir da subordinação dos interesses materiais a uma regra simbólica que o transcende (Caillé, 1998:8). No sistema de posse-dádiva, a exploração do trabalho, seja sob a forma de serviços seja sob a forma de meios de produção, escravos inclusive, é um elemento freqüente. Essa é uma relação diferente da escravatura como sistema (do escravagismo). No direito romano, que separava a "pecúnia" (riquezas como o gado e a colheita) da "família" (as riquezas da casa, como os escravos), vê-se que o trabalhador-escravo não é uma coisa, ou melhor, é uma coisa que tem "algo" (o mana, alma) que lhe é inerente e da qual não pode ser separado (Mauss, 2003:270). Correspondentemente, na nossa sociedade, o "produtor (...) sente que troca mais do que seu produto ou termo de trabalho, ele sente que dá algo de si: seu tempo, sua vida". Quer portanto ser recompensado, mesmo com moderação, por essa dádiva. "E recusar-lhe essa recompensa é incitá-lo à preguiça e ao menor rendimento" (Mauss, 2003:308). Como os romanos, que previam a revogação da doação devido à ingratidão (Justiniano (532) Código VIII, LVI, 10; apud Mauss, 2003:274), os trabalhadores individualizados que têm "a sensação aguda de que seu trabalho é revendido sem que tomem parte no lucro" (Mauss, 2003:314) precisam lutar para ver reconhecido (direito de arena, créditos, participações) o seu direito a manter um elo com o produto do seu esforço.

\section{Perspectivas}

A figura 3 sintetiza a interpretação que procedemos a partir dos dados da pesquisa: a tendência a um sistema diferenciado nas relações estruturais do trabalho e, conseqüentemente, da forma de administrá-lo, que implicaria uma mudança no cerne do entendimento dos sistemas de esforço-recompensa. As perspectivas que oferece não são, de todo, negativas. Hoje, como sempre, a economia de mercado se contorce para absorver as suas contradições. Nesse processo, as estruturas de produção sem serventia são descartadas. Outras estruturas a elas se superpõem. Não há, evidentemente, nenhum propósito, bom ou mau, nessas mutações. Mas, por coincidência ou fortuna, é possível que o trabalho individualizado venha a proporcionar o equilíbrio entre o individualismo e a moralidade, que Mauss postula no final do ensaio. 
Perspectivas do trabalho

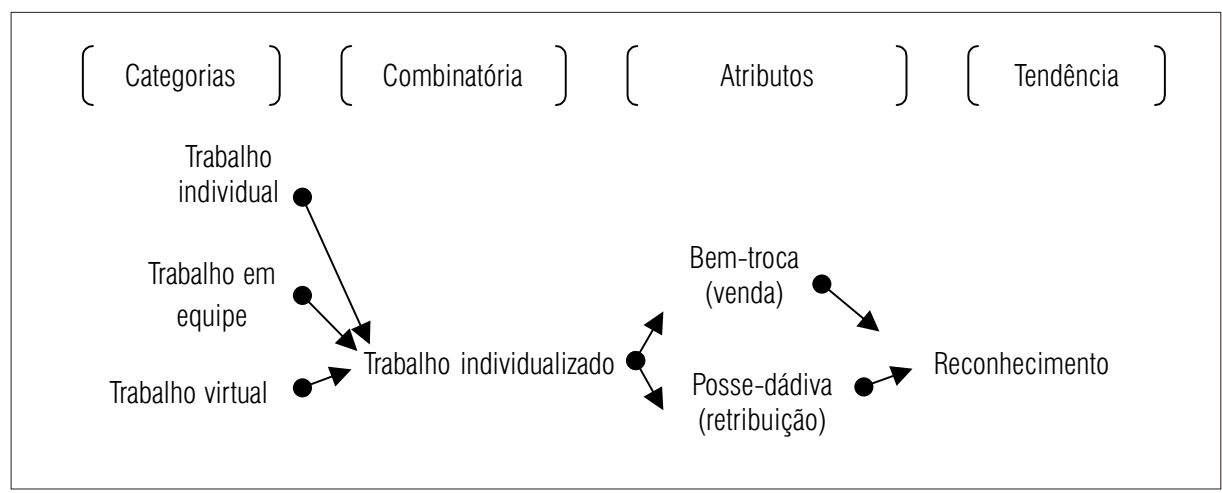

Recordemos que era a opinião de Durkheim ${ }^{3}$ (1930:101 e segs.), tio e mentor de Mauss, que quanto mais dividido, especializado e personalizado o trabalho, mais cada trabalhador depende da sociedade. Ele, como Mauss, pensava que a divisão econômica do trabalho não deve ser compreendida a partir das habilidades e capacidades do trabalhador, nem a partir dos seus resultados. Ela deve ser entendida a partir da sua "função", do "efeito moral" que produz. O trabalho cria o sentimento de solidariedade, tanto "mecânica", resultante do compartilhamento de crenças e valores, como "orgânica", de dependência uns dos outros. Na visão de Durkheim, essa prevalência da solidariedade orgânica dissolveria a estrutura segmentária da sociedade, diminuindo as distâncias que nos separam uns dos outros e dando uma "densidade moral" à vida em comum.

Embora não se possa igualar o conceito da /dádiva/ primitiva com o conceito de /presente/ contemporâneo (Parry, 1986), os bens transacionados como mercadorias têm sido transformados em posses, têm sido dotados de uma identificação pessoal. Ainda que adquiramos os bens como mercadorias, tratamos de personalizá-los. Convertemos mercadorias em posses. Decoramos nosso apartamento, incrementamos a eletrônica embarcada no nosso automóvel, combinamos, acrescentamos, reduzimos, individualizamos, enfim. Estabelecemos laços com os bens que transformamos em posse, ainda que os venhamos a alienar.

\footnotetext{
${ }^{3}$ Émile Durkheim (1858-1917), sociólogo francês. Fundador da sociologia centrada no estudo dos valores sociais e da alienação.
} 
O mesmo sentimento e a mesma prática cercam o trabalho individualizado. Nas sociedades da dádiva as transações são orientadas pela mobilização e pelo controle do trabalho, enquanto na sociedade capitalista as transações são comandadas pela mobilização e controle dos bens materiais (Carrier, 1991:130). Embora sejamos livres para mudar de emprego e de ocupação, a maioria das pessoas, mesmo constrangida pelo interesse econômico e pelas pressões sociais, prefere não fazê-lo. Na sociedade pós-industrial o trabalhador é, teoricamente, livre. Mas a liberdade do trabalhador é restrita. Ela é condicionada pela economia, pela estratificação em classes, pelo estamento a que pertencemos, e, também, pelas esferas cultural e psicológica que nos distinguem individualmente.

O trabalho individualizado permite, em alguma medida, a ampliação da nossa liberdade. Em primeiro lugar porque a apropriação dos resultados do trabalho em frações integrais de serviços, em lotes de produção, devolve a identidade ao trabalhador. O doador e o donatário do trabalho não são indivíduos que se definem independentemente do contexto social. São pessoas determinadas por suas posições, únicas em uma estrutura de relações sociais. São pessoas morais. A transação do trabalho individualizado pode levar à cordialidade ou hostilidade, mas ela não é indiferente (Blau, 1964:98). Em segundo, porque o trabalho individualizado altera o vínculo entre o trabalhador e a produção. O trabalhador está mais perto de um fornecedor de resultados do que de um empregado, no sentido que o termo teve ao longo do século XX: um assalariado vinculado permanentemente a uma única organização. O trabalho individualizado abre, talvez, a possibilidade de que o esforço produtivo seja "ao mesmo tempo necessário, obrigatório e voluntário" (Mauss, 2003).

\section{Referências bibliográficas}

BARKER, J. R. Tightening the iron cage: concretive control in self-managing teams. Administrative Science Quarterly, v. 38, n. 3, p. 408-437, Sept. 1993.

BARRON, J. M.; GZERDE, K. P. Peer pressure in a agency relationship. Journal of Labor Economics, n. 15, p. 234-254, 1997.

BARSADE, S. G. The ripple effect; emotional contagion and its influence of group behavior. Administrative Science Quarterly, v. 47, n. 4, Nov. 2002.

BARTEL, C. A.; SAAVEDRA, R. The collective construction of work group moods. Administrative Science Quarterly, v. 45, n. 2, p. 197-231, June 2000. 
BLAU, P. M. Exchange and power in social life. New York: John Wiley \& Sons, 1964.

CAILLÉ, A. Nem holismo nem individualismo metodológicos: Marcel Mauss e o paradigma da dádiva. Revista Brasileira de Ciências Sociais, v. 13, n. 38, out. 1998.

CARRIER, J. The symbolism of possession in commodity advertising. Man, v. 25, n. 4, p. 693-706, Dec. 1990.

. Gifts, commodities, and social relations: a Maussian view of exchange. Sociological Forum, v. 6, n. 1, p. 119-136, Mar. 1991.

DOSSE, F. História do estruturalismo. São Paulo: Universidade Estadual de Campinas, 1993.

DRUCKER, P. The coming of new organization. Harvard Business Review, p. 45-53, Jan./ Feb. 1988.

DURKHEIM, E. De la division du travail social. Paris: Presses Universitaires de France, 1930.

EARLEY, P. C.; SINGH, H. S. International and intercultural management research: what's next? Academy of Management Journal, v. 38, n. 2, p. 327-340, 1995.

FITZPATRICK, W. M.; BURKE, D. R. Competitive intelligence, corporate security and the virtual organization. Advances in Competitiveness Research, n. 11, 2003.

GIBSON, C. B.; ZELLMER-BRUHN, M. E. Metaphors and meaning: an intercultural analysis of the concept of teamwork. Administrative Science Quarterly, June 2001.

GODBOUT, J. T. O espírito da dádiva. Rio de Janeiro: FGV, 1999.

JACKSON, P. (Org.). Virtual working: social and organizational dynamics. London: Routledge, 1999.

JEHN, K. A. A multimethod examination of the benefits and determinants of intragroup conflict. Administrative Science Quarterly, v. 40, n. 3, p. 256-282, June 1995.

KATZEMBACH, J. R.; SMITH, D. The wisdom of teams: creating the high performance organization. Boston: Harvard Business School Press, 1993.

KIRMAN, B. L.; SHAPIRO, D. L. The impact of cultural values on job satisfaction and organizational commitment in self-managing work teams: the mediating role of employee resistance. Academy of Management Journal, v. 44, n. 3, p. 557-569, 2001.

KRONENFELD, D.; DECKER, H. W. Structuralism. Annual Review of Anthropology, n. 8, p. 403-541, 1979.

KURLAND, N. B.; EGAN, T. D. Telecommuting: justice and control in the virtual organization. Organization Science, v. 10, n. 4, p. 500-513, July/Aug. 1999. 
LANNA, M. Nota sobre Marcel Mauss e o "Ensaio sobre a dádiva". Revista de Sociologia Política, n. 19, p. 173-194, jun. 2000.

LEACH, E. As idéias de Lévi-Strauss. São Paulo: Cultrix, 1973.

LÉVI-STRAUSS, C. Anthropologie structurale. Paris: Plon, 1958.

. La pensée sauvage. Paris: Plon, 1962a.

. Les limites de la notion de structure en ethnologie. In: BASTIDE, R. (Org.). Sens et usages du terme structure. Haya: Mouton, 1962b.

. Les structures élémentaires de parente. Paris: Mouton, 1967.

. Introdução à obra de Marcel Mauss. In: MAUSS, M. Sociologia e antropologia. São Paulo: Cosac e Naif, 2003.

MAUSS, M. Ensaios de sociologia. São Paulo: Perspectiva, 2001.

. Sociologia e antropologia. São Paulo: Cosac e Naif, 2003.

MAYO, G. E. The human problems of industrial civilization. New York: The Macmillan Co., 1933.

PARRY, J. The 'gift', the Indian gift and the 'Indian Gift'. Man, n. 21, p. 453-473, 1986.

REED, M. The sociology of organizations: themes, perspectives and prospects. London: Harverster Wheatsheaf, 1992.

SARAVIA, E. J. Redes, organizações em rede e organizações virtuais. Revista Portuguesa e Brasileira de Gestão, v. 1, n. 1, abr./jun. 2002.

SEDIKIDES, C.; BREWER, M. B. Individual self, relational self, collective self. Philadelphia: Psychology Press, 2001.

SINCLAIR, A. The tyranny of a team ideology. Organization Studies, n. 13, p. 611-626, 1992.

STAPLES, S. D.; HULLAND, J. S.; HIGGINS, C. A. A self-efficacy theory explanation for the management of remote workers in virtual organization. Organization Science, v. 10, n. 6, p. 758-776, Nov./Dec. 1999. Special issue.

SUTTON, R. I. Maintaining norms about emotional expressions: the case of bill collectors. Administrative Science Quarterly, v. 36, n. 2, p. 245-268, June 1991.

TOMASKOVIC-DEVERY, D.; RISMAN, B. J. Telecommuting innovation and organization: a contingency theory of labor process change. Social Science Quarterly, v. 14, n. 2, p. 367385, 1993. 
VENKATESH, A.; VITALAVI, N. P. An emerging distributed work arrangement: an investigation of computer based supplemental work at home. Management Science, v. 38, n. 12, p. 1687-1706, Sept. 1992.

VIET, J. Los métodos estructuralistas en las ciencias sociales. Buenos Aires: Amorrurtu Editores, 1973.

WEBER, M. From Max Weber: essays in sociology. Translated and edited by H. H. Gerth and C.W. Mills. London: Routledge and Kegan, 1948.

WOOD, S.; ALBANESE, M. T. Can we speak of a high commitment management on the shop floor? Journal of Management Studies, n. 32, p. 215-247, 1997. 